\title{
SEMI-ANALYTICAL APPROACH TO ESTIMATE RAILROAD TANK CAR SHELL PUNCTURE
}

\author{
David Y. Jeong \\ Yim H. Tang \\ A. Benjamin Perlman \\ Volpe National Transportation Systems Center \\ Research and Innovative Technology Administration \\ US Department of Transportation \\ Cambridge, Massachusetts, USA
}

\section{ABSTRACT}

This paper describes the development of engineeringbased equations to estimate the puncture resistance of railroad tank cars under a generalized shell or side impact scenario. Resistance to puncture is considered in terms of puncture velocity, which is defined as the impact velocity at which puncture is expected to occur. In this context, puncture velocity represents a theoretical threshold limit. A given object striking the side of a tank car at an impact speed below the threshold velocity is not expected to penetrate the commodity-carrying tank. This definition for puncture velocity is similar to that for ballistic limit velocity, which is used to measure a target's ability to withstand projectile impact in military applications [1].

The term "semi-analytical" is used to characterize the current approach in developing equations for shell puncture in order to distinguish the present work from the semi-empirical approach used previously to develop equations corresponding to head puncture. While several tests have been conducted to study tank car head puncture, only a limited number of tests have been performed to study tank car shell puncture. The semi-analytical approach employs a combination of three tactics to deal with the paucity of test data. The first tactic applies collision dynamics to derive an idealized relationship between impact speed and maximum force for a generalized tank car shell impact scenario. Specifically, the principle of conservation of energy is applied. The second tactic applies computational methods to simulate tank car shell impacts in greater detail. Specifically, finite element analysis is used to examine the force-deformation behavior of different tank car configurations under different loading conditions. Regression analyses are performed on the results of the detailed finite element results to develop best-fit curves to account for the effects of various factors such as shell thickness, tank diameter, internal pressure and indenter size. The third tactic is empirical, in which various factors are related to puncture force using empirical formulas that have been developed in research to examine impact resistance in pipeline applications.

Results from applying the semi-analytical method to estimate shell puncture velocity are presented. Similarities and differences between the current method for shell puncture and the semi-empirical method for head puncture are discussed. In addition, results from sensitivity studies are presented to show the relative effect of different factors on estimated puncture velocity. These studies indicate that indenter size and internal pressure have the most significant effect on shell puncture velocity. Conversely, these studies indicate that tank diameter and ram car weight have a relatively weak effect on shell puncture velocity.

\section{INTRODUCTION}

Studies on railroad tank car head puncture were conducted by industry and government in the 1970s [2] and 1980s [3]. Based on these studies, equations were developed to calculate puncture velocity, i.e. the velocity at which puncture of the commodity-carrying tank is expected to occur for an assumed set of conditions. The term "semi-empirical" was used to describe the method because the functional forms of the equations comprising the method have a theoretical basis but certain constants in the equations were calibrated with test data 
[4]. Subsequently the methodology was modified to account for the presence of jackets and head shields [5].

Figure 1 shows a schematic of the generalized tank car head impact scenario described in the Code of Federal Regulations (CFR), Title $49 \S 179.16$, Specifications for Tank Cars. A moving ram car strikes the head of a subject tank car below the centerline of the head. The impact location on the tank head is specified in Appendix A to Part 179 as a certain height above the top of the sill. The subject tank car with its brakes released is braced for the impact of the ram car by three fully-loaded backup cars with their brakes applied.

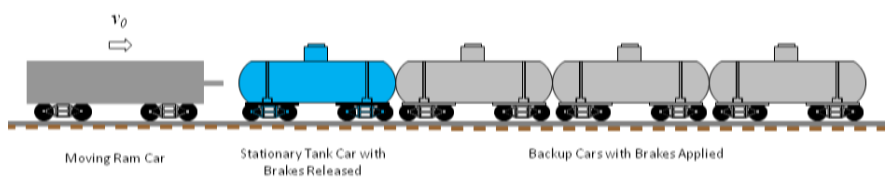

Figure 1: Generalized Tank Car Head Impact Scenario

Puncture velocities calculated using the semi-empirical equations were compared to head-impact test data from several sources. The comparisons indicated that the estimates for puncture velocity tend to be conservative [6-7]. In this context, conservative means that puncture is expected to occur at velocities greater than the calculated value. In other words, the actual puncture velocity is most likely to be higher than that calculated by the semi-empirical method.

Prior to 2007, no research had been conducted to examine the structural integrity and crashworthiness of railroad tank cars under shell impacts. In 2007, full-scale tests and analyses were performed to examine the structural response of tank cars in the generalized shell impact scenario shown schematically in Figure 2. A moving ram strikes the side of a tank car at its centerline as it is braced against a rigid wall. Dow Chemical Company provided the tank cars for these full-scale shell impact tests, which were conducted under the Next-Generation Rail Tank Car (NGRTC) project [8]. In addition, the test effort was supported by finite element and collision dynamics analyses conducted by the Volpe National Transportation Systems Center (Volpe Center) [9]. Subsequent Volpe Center research examined the force-indentation behavior and puncture of tank cars under the generalized shell impact scenario for different shell thicknesses and indenter sizes [10]. Results from this previous research are used in the work described in this paper.

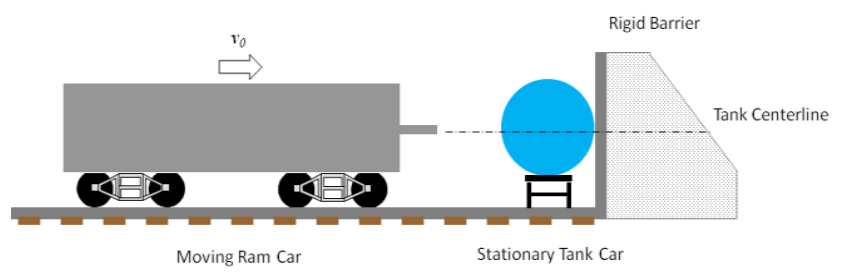

Figure 2: Generalized Tank Car Shell Impact Scenario
This paper describes the development of an engineeringbased methodology to facilitate the estimation of puncture velocity in generalized tank car shell impacts. The methodology uses a combination of three tactics to deal with the paucity of data on tank car shell puncture. The first tactic is the application of engineering principles, specifically the conservation of energy, to derive an idealized relationship between impact speed and maximum impact force for a tank car shell impact scenario. The second tactic is the application of computational methods to simulate tank car shell impacts. Specifically, finite element analysis is applied to simulate different tank car configurations (i.e., shell thicknesses and tank diameters) under different loading conditions (i.e. indenter sizes). The third tactic is empirical, in which various factors are related to puncture force using empirical formulas that have been developed in research to examine impact resistance in pipeline applications.

\section{SEMI-ANALYTICAL APPROACH}

The term "semi-analytical" is used to characterize the equations comprising the present methodology because their derivation is based largely on collision dynamics and finite element analyses that have been confirmed by a limited number of shell impact tests. The semi-analytical method for shell impacts mimics the semi-empirical approach for head impacts to account for jacket thickness and standoff distance. Moreover, the equations presented in this paper provide the basis for an engineering framework to facilitate the estimation of tank car shell puncture velocity. Such a framework complements the semi-empirical equations previously developed to calculate puncture velocity for head impacts.

\section{Using Collision Dynamics}

Theoretical collision dynamics are used to derive an idealized relationship between impact speed and maximum force in a generalized shell impact scenario. Specifically the principle of conservation of energy is applied, in which the kinetic energy of the moving ram car is set equal to the energy required to stop the ram car. Kinetic energy is defined as

$$
K E=1 / 2 m v_{0}^{2}
$$

where $m$ is the mass of the moving ram car and $v_{0}$ is the impact velocity. In the present development, the energy to stop the ram car is assumed to be equal to the strain energy due to deformation, or the area under the force-indentation curve:

$S E=\int_{0}^{\delta_{\max }} F(x) d x$

where $\delta_{\max }$ is the maximum indentation. This last assumption implies that the maximum force and the maximum indentation occur simultaneously. In addition, the functional form of the force-indentation curve is assumed to be a power-law relation: 
$F=k \delta^{n}$

where $\delta$ is the indentation. Moreover, this functional form of the force-indentation curve facilitates integration of equation (2) and provides a closed-form expression for strain energy. Furthermore it is assumed that the value of $k$ depends on the tank geometry (i.e. shell thickness and diameter), internal pressure and indenter size. Results from finite element analysis simulations are used to calculate specific values of $k$, which are discussed in the next section of this paper. Meanwhile, the value of the exponent $n$ is assumed to be fixed. In severe impacts, plastic deformation of the tank typically occurs, in which case the value of the exponent in power-law relation for force-indentation is a positive number less than one (i.e. $0<n<$ 1). In the development of semi-empirical equations for tank car head puncture [4], Hertz contact was assumed, which corresponds to a value of $n$ equal to $3 / 2$. The Hertz theory assumes elastic contact between impacting bodies. However, the force levels associated with collisions and train accidents are likely to create permanent plastic deformations for which the Hertz contact theory is not applicable. In the present development, $n$ is equal to $1 / 2$. The basis for this assumption is also discussed in the next section of this paper.

Figure 3 shows a schematic of a force-indentation curve in which the shaded area under the curve represents the strain energy due to deformation. The shape of the force-indentation curve implies plastic deformation. In addition, increasing impact speed is implied in the force-indentation curve; i.e. greater indentations and correspondingly higher force levels will occur as the impact speed is increased. When the impact speed reaches a critical value, the localized plastic strain in the tank will exceed the load-bearing strength of the material. At this point, failure by puncture of the commodity-carrying tank is expected to occur. However, the precise impact speed at which failure occurs is bounded by the inherent scatter associated with material properties. Therefore, three regions are labeled in the schematic to represent possible outcomes in terms of failure.

A closed-form expression for maximum force as a function of impact velocity can be derived by substituting equation (3) into (2) and integrating the strain energy equation:

$F_{\text {max }}=k\left[\frac{n+1}{2} \frac{m}{k} v_{0}^{2}\right]^{\frac{n}{n+1}}$

In the current methodology, the impact speed reaches the critical value or puncture velocity when the maximum force reaches the puncture force of the tank. Empirical equations are used to relate the various factors to puncture force, which are described later in this paper.

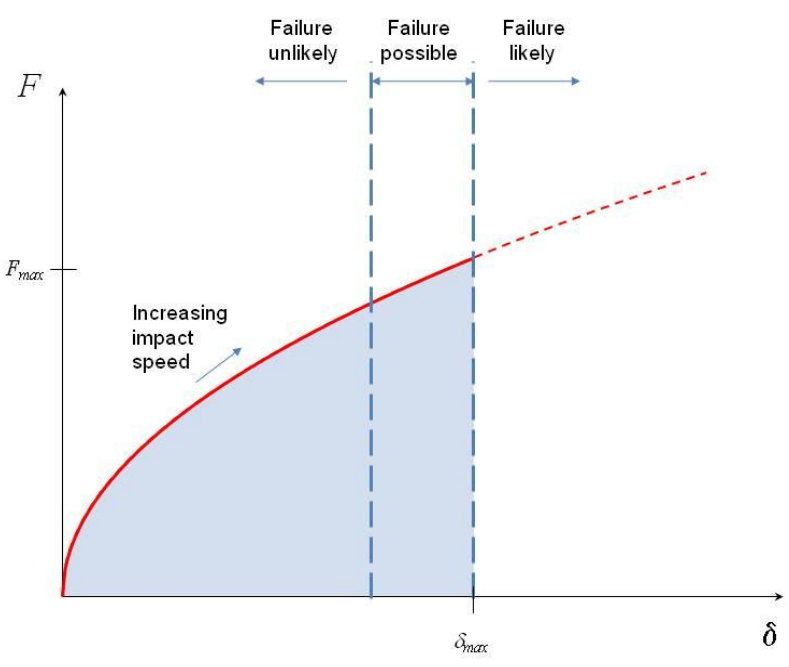

Figure 3: Generic Force-Indentation Curve

\section{Using Results from Finite Element Analysis}

Dynamic, nonlinear finite element analysis (FEA) was conducted in previous work to examine the force-indentation behavior of tank cars in generalized shell impacts [9-10]. In this context, dynamic means the simulations were performed with explicit FEA codes. Nonlinear means that elastic-plastic stress-strain behavior was assumed in conjunction with large deformations. In addition, fluid-structure interaction was included in the FEA analysis. In some case, the initiation and evolution of damage leading the catastrophic failure of commodity-carrying tank was included to calculate puncture velocity.

Three full-scale shell impact tests were conducted under the NGRTC project [8]. The tank cars used in these tests weighed 263,000 lb. In addition, they contained fluid with the approximate density of liquid chlorine with an outage of 10.6 percent, and were pressurized to $100 \mathrm{psi}$.

Two of the full-scale tests were instrumented to capture the force-indentation behavior of the tank during impact. Figure 4 compares the measurements of force and indentation with calculations from finite element analysis of these two tests. A relatively large indenter (17 inches in height by 23 inches in width) was used in Test 1 , in which the integrity of the tank was maintained. A smaller ( 6 inch by 6 inch) indenter was used in Test 2 which punctured the tank. The regression curve in the figure refers to the power-law relation in equation (3) with the exponent $n$ equal to $1 / 2$. A closed-form solution to the rigid-plastic deformation of tubes under different loading and boundary conditions also corroborates the 1/2-power law exponent in force-indentation characteristic [11]. Moreover, the power-law regression curve provides a reasonable approximation of the force-indentation curve of the full-scale tests. For these reasons, the exponent is held constant and assumed to be to $1 / 2$ in remainder of this paper. 


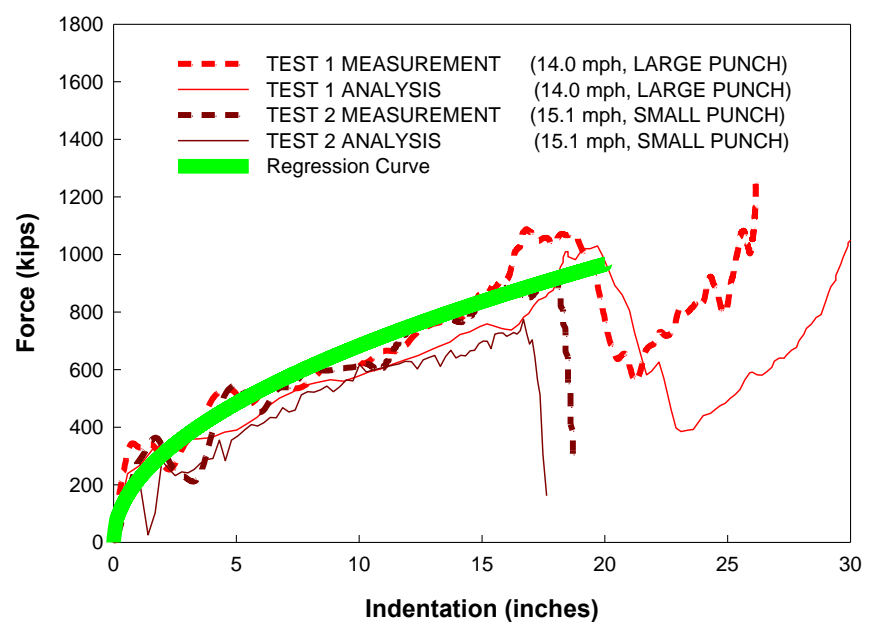

Figure 4: Force-Indentation Curves in Full-scale Shell Impact Tests

In the current methodology, the effect of different factors on the force-indentation behavior is embedded in the $k$-term in equation (3). That is, the value of $k$ is depends on shell thickness, internal pressure, tank diameter, and indenter size. Moreover, regression or best-fit curves are developed from dynamic, nonlinear finite element analysis results to account for these dependencies. The calculation of $k$ is carried out by multiplying a series of factors that are functions of shell thickness, internal pressure and tank diameter. Thus, for a fixed indenter size:

$$
k\left(h, p_{i}, D\right)=a_{0}+a_{1} h+a_{2} h^{2} \cdot \lambda_{1}\left(p_{i}, D\right) \cdot \lambda_{2}(D)
$$

In addition, the coefficients $a_{0}, a_{1}$ and $a_{2}$ are assumed to depend on indenter size. Based on a closed-form solution for rigidplastic indentation of tubes [11], the following functional form is assumed for the dimensionless factor to account for internal pressure:

$\lambda_{1}\left(p_{i}, D\right)=\sqrt{1-\frac{p_{i}}{p_{0}(D)}}$

where $p_{i}$ is the internal pressure and $p_{0}$ depends on tank diameter. The following regression curve is derived from results of finite element analysis for shell impacts:

$$
p_{0}=87.8-89.8\left(\frac{D}{100}\right)+27.8\left(\frac{D}{100}\right)^{2}
$$

Another dimensionless factor is used to account explicitly for the effect of tank diameter using a parabolic curve fit:
$\lambda_{2}=0.969+0.288\left(\frac{D}{100}\right)-0.275\left(\frac{D}{100}\right)^{2}$

Three different indenters were considered in previous finite element simulations of generalized tank car shell impacts [10]. The edges of these indenters are rounded. Referring to Figure 5, Table 1 lists the relevant dimensions for the footprint of these indenters.

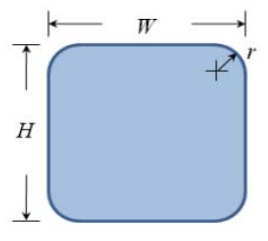

Figure 5: Schematic of Indenter Footprint

Table 1: Dimensions of Different Indenters

\begin{tabular}{|c|c|c|c|}
\hline & $\begin{array}{c}\text { Height, } H \\
\text { (inches) }\end{array}$ & $\begin{array}{c}\text { Width, } W \\
\text { (inches) }\end{array}$ & $\begin{array}{c}\text { Edge radius, } r \\
\text { (inch) }\end{array}$ \\
\hline 1 & 6 & 6 & $1 / 2$ \\
\hline 2 & 12 & 12 & 1 \\
\hline 3 & 17 & 23 & 1 \\
\hline
\end{tabular}

Regression curves for $k$ as a function of shell thickness and indenter size were derived from the previous finite element results. Regression curves to account for the dependence of $k$ on internal pressure and tank diameter were derived from additional FEA results conducted for this paper. Table 2 lists the values of the coefficients used in equation (5) to account for different indenters.

Table 2: Coefficients for Different Indenters

\begin{tabular}{|c|c|c|c|}
\hline & $a_{0}$ & $a_{1}$ & $a_{2}$ \\
\hline 1 & 66.1 & -13.0 & 42.8 \\
\hline 2 & 69.2 & -17.1 & 42.7 \\
\hline 3 & 63.1 & 12.1 & 20.7 \\
\hline
\end{tabular}

In the semi-empirical equations for tank car head puncture, the modification to account for the presence of jackets and head shields is summation of the individual thicknesses to calculate an equivalent or effective thickness of a single plate. The additive nature of this equivalent thickness calculation implies that the layering is commutative. In other words, changing the order of layering does not change the outcome in terms of puncture. Consequently, the puncture velocity associated with a thick jacket combined with a thin tank is the same for a thin jacket combined with a thick tank as long as the added thicknesses are equal. In the present methodology, an effective thickness is calculated for jacketed tank cars: 


$$
h_{e f f}=h_{S}+h_{J}
$$

where $h_{S}$ is the shell thickness and $h_{J}$ is the jacket thickness (typically 11-gauge or 0.119 inch). Moreover, the effective thickness is used wherever $h$ appears in these equations.

\section{Using Empirical Equations}

The failure mechanics associated with puncture involve complex interactions between plastic bending, stretch, tearing, and mechanical properties of tank car steels. However, a simplifying assumption is applied in the development of both the semi-empirical equations for head puncture and the semianalytical equations for shell puncture. In both cases, puncture force is related to a shear failure criterion [4]. That is, failure by puncture was assumed to occur when the maximum stress exceeds the ultimate shear strength of the tank material. In the case of head puncture, the transverse shear component of stress was calculated for a flat circular plate subjected to a concentrated load offset from the center to represent a knuckle impact on a tank head. Moreover, this application of plate theory provided a means to relate puncture force to factors such as perimeter of the impressed area, tank head thickness and ultimate tensile strength of the tank head material.

The failure mechanics associated with puncture have been studied in other applications such as buried onshore oil and natural gas transmission pipelines. The integrity of pipelines may be threatened by puncture during digging operations using excavators and backhoes. Results from testing and analysis indicate that puncture force for line pipe is strongly dependent on the size of the excavator tooth (analogous to indenter size in tank car impacts), pipe wall thickness and material properties [12-15]. In addition, puncture force in this application is insensitive to pipe diameter and internal pressure.

Some of the research on impact strength in the pipeline application has been empirical. For example, the following empirical equation for puncture force is assumed in the present development for tank car shell puncture, which is similar in mathematical form to one that was considered in the studies of pipeline puncture and tank car head puncture:

$$
F_{p}=C_{1} P^{a} h \sigma_{U}{ }^{b}
$$

where $P$ is the perimeter of the indenter footprint, $h$ is the shell thickness and $\sigma_{U}$ is the ultimate tensile strength of the shell material. The perimeter of the indenter footprint is

$$
P=2 H+W-4-\pi r
$$

In equation (10), $a, b$ and $C_{l}$ are constants, which are determined using results from detailed finite element analyses. These analyses accounted for the initiation and evolution of material damage, and were confirmed by the data from the full- scale shell impact tests [10]. Based on the FEA results $a, b$ and $C_{l}$ are equal to $0.6,0.8$ and 4.19 respectively.

Puncture velocity is calculated by setting the maximum force in equation (4) equal to puncture force in equation (10):

$v_{0}=\frac{1}{17.6 k\left(h, p_{i}, D\right) \sqrt{m}} C_{2} P^{0.907} h \sigma_{U}^{1.202}$

where $C_{2}$ is equal to 9.912 , and the values for exponents $n, a$ and $b$ have been substituted. In addition, the factor of 17.6 has been included to convert the units of velocity from inches per second to miles per hour.

Equation (12) represents the puncture velocity for tank cars without a jacket. For jacketed tank cars, a multiplying factor is applied, which accounts for the presence of the jacket and for the gap or standoff distance, which is usually 4 inches. Such a factor was developed of the semi-empirical equations for head puncture. In the tank car head impact tests, a small but measureable reduction in impact velocity was observed when a coupler hits a head shield and then when it hits the commoditycarrying tank because the head shield is generally placed with a gap distance between it and the tank. The reduction in impact velocity was estimated in the semi-empirical method for head puncture by applying the principle of conservation of energy. A similar gap factor is derived in the semi-analytical method for shell puncture for jacketed tank cars:

$v_{p}=K_{G} \cdot v_{0}$

where $v_{p}$ is the velocity to puncture the commodity-carrying tank, $v_{0}$ is the impact velocity when the indenter strikes the jacket and $K_{G}$ is the so-called gap factor. From the conservation of energy,

$1 / 2 m v_{0}^{2}+F_{p} \cdot \Delta=1 / 2 m v_{p}^{2}$

where $F_{p}$ is the puncture force and $\Delta$ is the gap or standoff distance between the jacket and the commodity-carrying tank. The gap factor is derived as

$$
K_{G}=\sqrt{1+\frac{2 F_{p} \Delta}{m 17.6 v_{0}^{2}}}
$$

The physical interpretation of this so-called gap factor is that the puncture velocity for a jacketed tank car is higher than that of a non-jacketed car. Moreover, this factor would account for the ability of the jacket to blunt the load of an impacting object. Using this factor, the puncture velocity of jacketed tank car is generally about 10 percent higher than that of a non-jacketed tank car. 


\section{RESULTS}

Figure 6 shows results from applying the semi-analytical method to estimate shell puncture velocity as a function of shell thickness and indenter size. These results are based on the following assumptions: ram car weight of 286 kips, tank diameter of 100 inches, internal pressure of $100 \mathrm{psi}$, and ultimate tensile strength of $81 \mathrm{ksi}$ for TC-128B steel. In addition, these results include the presence of an 11-gauge (i.e. 0.119 inch thick) jacket.

The open circles in Figure 6 represent results from the FEA simulations that include material failure. The solid symbols in the figure were calculated from applying the semianalytical method described in this paper. Each solid symbol has error bars that represent $\pm 1.5 \mathrm{mph}$ variation from the calculated puncture velocity. The variation in puncture velocity attempts to quantify the region of possible failure shown schematically in Figure 3. The magnitude of this variation (i.e. $1.5 \mathrm{mph}$ ) corresponds to a variation of one standard deviation from the average measurement of ultimate tensile strength conducted on samples of TC-128B during a test program to characterize steels obtained from tank cars retired from the fleet [16]. The variation in puncture velocity associated with the scatter in material properties is described further in the Discussion section.

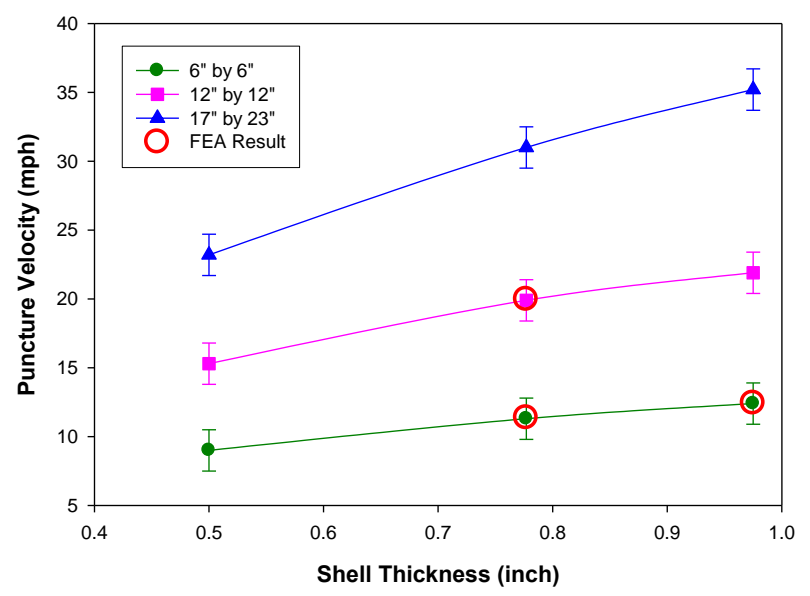

Figure 6: Estimated Shell Puncture Velocity as a Function of Shell Thickness and Indenter Size

\section{SENSITIVITY STUDIES}

Sensitivity studies are performed to show the relative effect of different factors that enter into the semi-analytical equations developed to estimate tank car shell puncture. Baseline values are assumed for each of the different factors, and then varied one factor at a time while holding the other factors equal to their baseline values to calculate the difference in estimated puncture velocity. Table 3 lists the different factors that are considered in the sensitivity studies along with their corresponding baseline values.
Table 3: Factors and Assumed Baseline Values

\begin{tabular}{|l|c|}
\hline Factor & $\begin{array}{c}\text { Baseline } \\
\text { Value }\end{array}$ \\
\hline Indenter size & 12 " $\times 12$ " \\
\hline Shell thickness & 0.777 inch \\
\hline Ultimate tensile strength & $81 \mathrm{ksi}$ \\
\hline Ram car weight & $286 \mathrm{kips}$ \\
\hline Tank diameter & 100 inches \\
\hline Internal pressure & $100 \mathrm{psi}$ \\
\hline Jacket thickness & 0.119 inch \\
\hline
\end{tabular}

Figure 7 illustrates the relative sensitivity of the factors considered in these studies. The figure shows that the puncture velocity is $19.9 \mathrm{mph}$ when the baseline values for each of the factors are assumed. The factors are arranged to illustrate the reduction on puncture velocity from the baseline. In addition, the figure shows the range of assumed values for each factor and the corresponding change in estimated puncture velocity from the baseline. For example, changing the indenter from the 12-inch by 12 -inch baseline to the 6-inch by 6-inch indenter, changes the puncture velocity from $19.9 \mathrm{mph}$ baseline to 11.3 mph. Decreasing the shell thickness from 0.777 inch to $1 / 2$ inch decreases the puncture velocity from the baseline to $15.3 \mathrm{mph}$. Conversely, increasing the shell thickness to 0.975 inch increases the puncture velocity to $21.9 \mathrm{mph}$. The effect of material properties is represented by ultimate tensile strength which has a similar effect as shell thickness. That is, the estimated puncture velocity increases or decreases as the ultimate tensile strength increases or decreases. The assumed range of values for the ultimate tensile strength corresponds to \pm 2 standard deviation from the mean based tensile test measurements on TC-128B [16]. The figure also shows that puncture velocity decreases when the 11-gauge jacket is removed. Tank diameter is shown to have a relatively weak effect on puncture velocity. The difference between a 90-inch diameter tank and 120-inch diameter tank is slightly more than $0.5 \mathrm{mph}$. The ram car weight of $286,000 \mathrm{lb}$ is considered as a worst-case assumption because real-life accidents do not always involve cars with the heaviest gross rail weight. However, the difference in puncture velocity for a ram car weighing 286 kips and 263 kips is shown to be relatively small. The effect of internal pressure is shown to be significant. The tank structure becomes more compliant when the internal pressure is reduced, which requires more energy and therefore greater velocity to cause puncture than a stiffer tank. Moreover, the length of the bars in Figure 7 symbolizes the relative effect of each factor on puncture velocity. Therefore, internal pressure and indenter size are shown to have the most significant effect on shell puncture velocity. Conversely, ram car weight and diameter have a relatively weak influence on shell puncture velocity, at least for the range of values considered. 


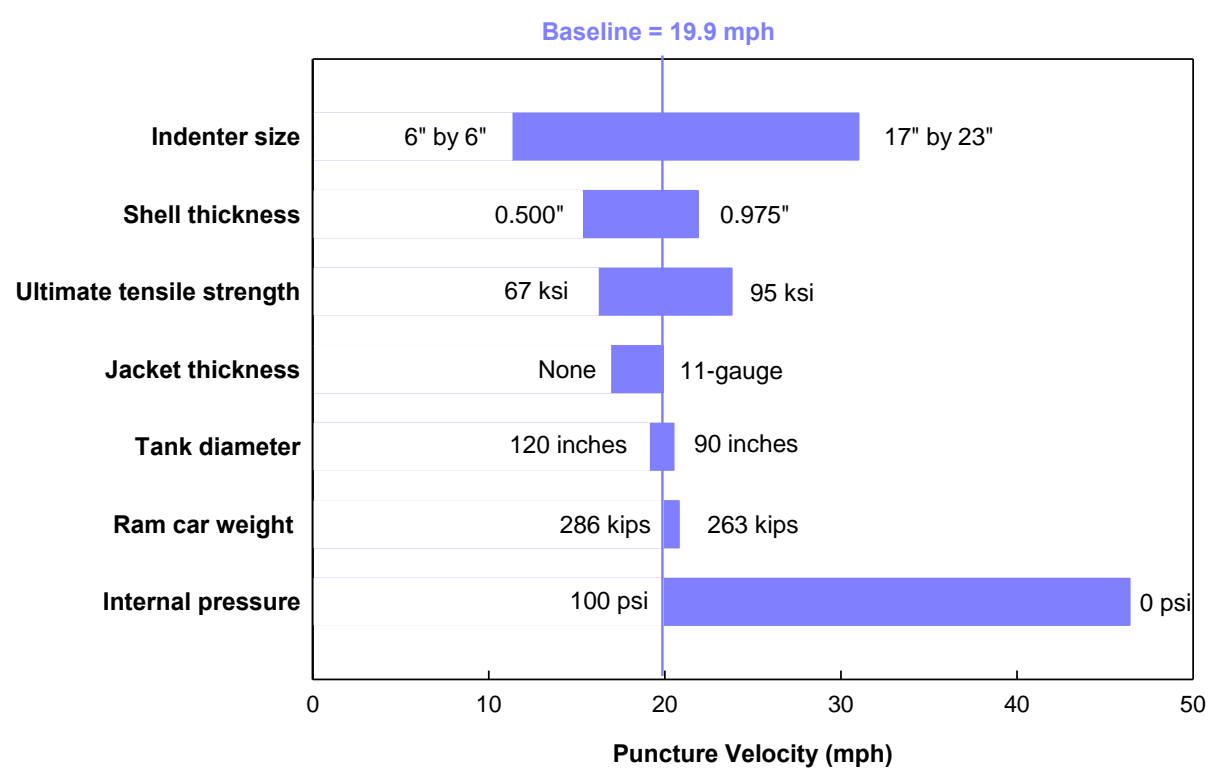

Figure 7: Relative Effect of Various Factors on Shell Puncture Velocity

\section{DISCUSSION}

Similar sensitivity studies can be conducted to examine the relative effect of different factors on head puncture velocity using the semi-empirical method. The original semi-empirical method was modified to account explicitly for indenter size. Figure 8 shows results from such studies, considering the same factors as in the shell puncture studies. The range of assumed values for the factors is also the same except for an additional case of a $1 / 2$-inch head shield for protection. The head shield case is shown to provide an improvement in puncture resistance over the baseline case of an 11-gauge jacket. That is, using a $1 / 2$-inch head shield increases the puncture velocity by $5 \mathrm{mph}$ compared to a bare head, and by about $2 \mathrm{mph}$ compared to a jacketed tank head. In comparing the relative effect of the various factors on head and shell puncture velocity, similarities and differences are evident. In both cases, for example, indenter size is shown to have a relatively strong effect on puncture velocity while the effect of ram car weight is relatively weak. However, internal pressure is shown to have a significant effect on shell puncture velocity, but its effect on head puncture velocity is not as strong. The remaining factors have relatively moderate effects on puncture velocity in both head and shell cases.

In the semi-empirical equations for head puncture and the semi-analytical equations for shell puncture, the force at which puncture is expected to occur is directly related to the ultimate tensile strength of the tank material. However, measurements of mechanical properties such as ultimate tensile strength exhibit inherent scatter, which can lead to uncertainty in predictions of puncture. For example, standard tensile tests on material extracted from tank cars retired from the fleet indicate that the standard deviation for the ultimate tensile strength of TC-128B steel is between 6 and $7 \mathrm{ksi}$ [16]. The scatter associated with \pm one standard deviation variance corresponds to $\pm 1.5 \mathrm{mph}$ in the estimation of shell puncture velocity.

The effect of strain rate has not been studied explicitly in the present work. However, measurements of the strength properties for TC-128B steel at different strain rates were conducted under the NGRTC project [8]. Figure 9 shows measurements of yield strength and ultimate tensile strength as a function of strain rate, and a power-law regression formula for each strength property. The figure also shows the scatter band corresponding to \pm 2 standard deviations in these strength properties from their average values at nominally low strain rate (i.e. the strain rate at which tensile test measurements are normally conducted). The regression curves indicate that yield strength and ultimate tensile strength tend to increase with increasing strain rate. But the figure also shows that the strength properties measured at relatively high strain rate are within the scatter bands of the strength properties conducted at nominally low strain rate.

Evaluations of the semi-empirical method to estimate tank car head puncture velocity revealed that the method tends to be conservative [6-7]. That is, the velocity at which head puncture is expected to occur is likely to be greater than the speed predicted by the semi-empirical approach. The observed trend of the semi-empirical method was based on comparisons with results of head puncture test data from several sources. To date, however, only one full-scale tank car shell puncture test has been conducted. Therefore, a similar conclusion cannot be drawn to assess whether the semi-analytical approach will consistently provide conservative (or non-conservative) predictions for shell puncture. On one hand, estimates of puncture velocity based on finite element analysis are expected to be less conservative as those based on the semi-empirical method. But on the other hand, the conservation of energy 
assumes that the entire kinetic energy is dissipated through plastic deformation of the tank, which is a conservative assumption. In addition, the gap factor developed to account for the standoff distance between a jacket and the commoditycarrying tank is also based on energy conservation. However, the benefit of the jacket in terms of protection is its ability to blunt load since its energy absorption capability is negligible. Therefore, applying the gap factor for jacketed cars might tend to overestimate the actual puncture velocity.

Development of a performance standard for tank car puncture is a continuing topic of interest for both industry and government. Moreover, an open question is whether such a standard can be based on the ability to predict puncture velocity in lieu of actual testing. The semi-empirical method for head puncture and the semi-analytical methodology described in this paper for shell puncture may represent the initial steps in developing a rational basis for such a performance standard.

\section{CONCLUDING REMARKS}

This paper describes the development of a semi-analytical methodology to facilitate the calculation of puncture velocity for railroad tank cars involved in a generalized shell impact scenario. The approach in the development combines three tactics: (1) applying collision dynamics to derive an idealized, closed-form expression between impact speed and maximum force, (2) employing results from detailed finite element analyses to characterize the effects of various factors on impact force, and (3) using empirical relations to relate these factors to puncture. Moreover, this methodology provides a framework to estimate shell puncture velocity in light of limited test data on tank car shell impacts.

The test data to validate the semi-analytical methodology is limited two full-scale shell impact tests, only one of which resulted in failure by puncture. Therefore, the application of the methodology to predict puncture under the generalized shell impact scenario should be carefully considered. Despite the paucity of test data, the current methodology is well suited to conduct comparative studies to evaluate the performance of different tank car configurations, in terms of puncture velocity, in which factors such as tank thickness, tank diameter and internal pressure are varied. Therefore, the methodology is applied to conduct sensitivity studies to examine the relative effect of different factors on shell puncture velocity. Results from sensitivity studies indicate that indenter size and internal pressure have the most significant effect on shell puncture velocity. Conversely, tank diameter and ram car weight are shown to have a relatively weak effect on shell puncture velocity.

Moreover, the current methodology developed for shell puncture provides a complementary framework to the semiempirical method previously developed to estimate puncture velocity for head impacts.

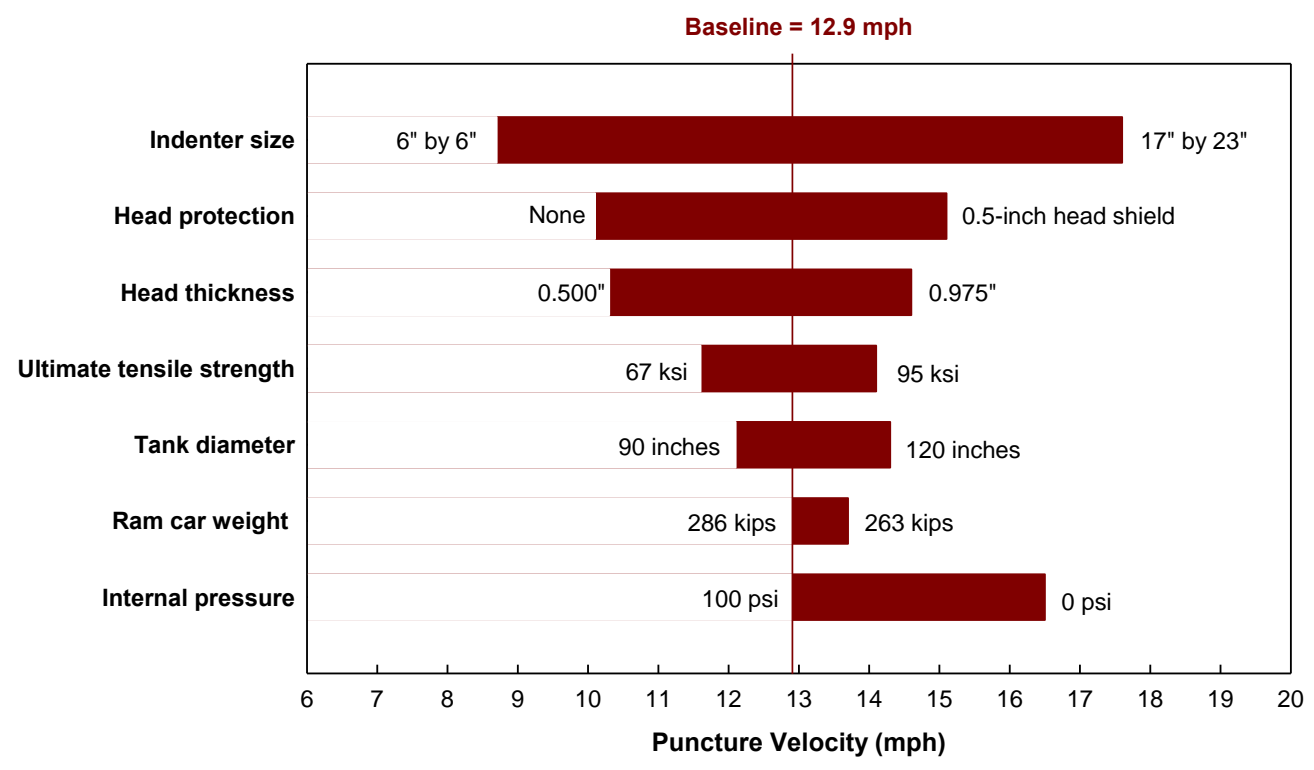

Figure 8: Relative Effect of Various Factors on Head Puncture Velocity 


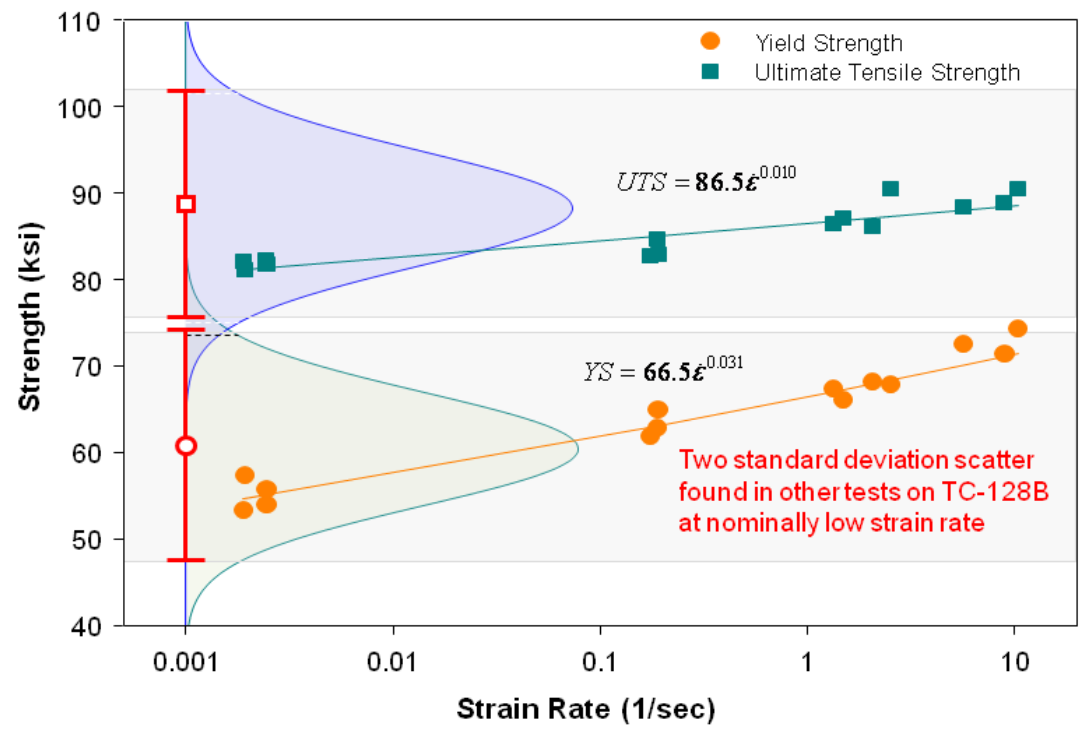

Figure 9: Effect of Strain Rate on Strength Properties of TC-128B and Scatter at Nominally Low Strain Rate

\section{NOMENCLATURE}

a exponent

$b \quad$ exponent

$C_{1} \quad$ constant

$C_{2} \quad$ constant

D tank diameter

$F \quad$ impact force

$F_{p} \quad$ puncture force

$H \quad$ indenter height

$h \quad$ thickness

$h_{\text {eff }} \quad$ effective thickness

$h_{J} \quad$ jacket thickness

$h_{S} \quad$ shell thickness

$K E \quad$ kinetic energy

$K_{G} \quad$ dimensionless gap factor

$k \quad$ constant in power-law relation

$m \quad$ ram car mass

$n \quad$ exponent in power-law relation

$P \quad$ perimeter of indenter footprint

$p_{i} \quad$ internal pressure

$r \quad$ edge radius

$S E \quad$ strain energy

$v_{0} \quad$ impact velocity

$v_{p} \quad$ puncture velocity

$W \quad$ indenter width

$\Delta \quad$ gap or standoff distance

$\delta \quad$ indentation

$\lambda_{1}$ dimensionless factor for internal pressure

$\lambda_{2}$ dimensionless factor for tank diameter

$\sigma_{U} \quad$ ultimate tensile strength

\section{ACKNOWLEDGMENTS}

The work described in this paper was sponsored by the Federal Railroad Administration (FRA), Office of Research and Development. Mr. Kevin Kesler is the Chief of the Equipment and Operating Practices Division. Mr. Francisco Gonzalez is the project manager for research on railroad tank cars and hazardous materials. Discussions with Mr. Karl Alexy of the FRA Office of Safety are greatly appreciated.

\section{REFERENCES}

[1] J.A. Zukas, T. Nicholas, H.F. Swift, L.B. Greszczuk, D.R Curran, 1982: Impact Dynamics, John Wiley \& Sons, Inc.

[2] E.A. Phillips, L. Olsen, 1972: "Final Phase 05 Report on Tank Car Head Study," RPI-AAR Tank Car Safety research and Test Project, RA-05-17.

[3] M. Coltman, M. Hazel, 1992: "Chlorine Tank Car Puncture Resistance Evaluation," Volpe Center Final Report DOT/FRA/ORD-92/11.

[4] J.C. Shang, J.E. Everett, 1972: "Impact Vulnerability of Tank Car Heads," Shock and Vibration Bulletin 42, 197 210.

[5] S.M. Belport, 1993: "Evaluation of the Puncture Resistance for Stainless Steel and Carbon Steel Tank Heads," AAR Report No. P-93-114.

[6] D.Y. Jeong, Y.H. Tang, A.B. Perlman, 2001: "Evaluation of Semi-Empirical Analyses for Railroad Tank Car Puncture Velocity, Part I: Correlations with Experimental Data," Volpe Center Final Report DOT/FRA/ORD01/21.1.

[7] D.Y. Jeong, Y.H. Tang, A.B. Perlman, 2006: "Engineering Analyses of Railroad Tank Car Head Puncture Resistance," Proceedings of the 2006 ASME International 
Mechanical Engineering Congress and Exposition, IMECE2006-13212.

[8] S.W. Kirkpatrick, 2009: "Detailed Puncture Analyses of Various Tank Car Designs," ARA Final Technical Report, Prepared for the Next Generation Rail Tank Car (NGRTC) Project.

[9] Y.H. Tang, H. Yu, J.E. Gordon, M. Priante, D.Y. Jeong, D.C. Tyrell, A.B. Perlman, 2007: "Analysis of Full-Scale Tank Car Shell Impact Tests," Proceedings of the 2007 ASME Rail Transportation Division Fall Technical Conference, RTDF2007-46010.

[10] Y.H. Tang, H. Yu, J.E. Gordon, D.Y. Jeong, A.B. Perlman, 2008: "Analysis of Railroad Tank Car Shell Impacts Using Finite Element Method," Proceedings of the 2008 IEEE/ASME Joint Rail Conference, JRC2008-63014.

[11] T. Wierzbicki, M.S. Suh, 1988: Indentation of Tubes under Combined Loading," International Journal of Mechanical Sciences 30, 229-248.
[12] A. Palmer, A. Neilson, S. Sivadasan, 2003: "Impact resistance of pipelines and the loss-of-containment limit state," Journal of Pipeline Integrity 2, 231-240.

[13] D.C. Brooker, 2003: "Numerical modeling of pipeline puncture under excavator loading, Part I. Development and validation of finite element material failure model for puncture simulation," International Journal of Pressure Vessels and Piping 80, 715-725.

[14] D.C. Brooker, 2003: "Numerical modeling of pipeline puncture under excavator loading, Part II. Parametric study," International Journal of Pressure Vessels and Piping 80, 727-735.

[15] D.C. Brooker, 2005: "Experimental puncture loads for external interference of pipelines by excavator equipment," International Journal of Pressure Vessels and Piping 82, 825-832.

[16] P.C. McKeighan, 2007: "Mechanical Properties of Tank Car Steels Retired from the Fleet," Southwest Research Institute Report to the Volpe Center. 